\title{
La civilización como modelo de vida en el Madrid del siglo XVIII
}

\author{
JOAQUín ÁlVAREZ BARRIENTOS \\ CSIC, Madrid
}

\begin{abstract}
No pretendo en esta ocasión describir usos y costumbres -que se pueden encontrar en diversas fuentes-, sino acercarme a la vida de la ciudad de Madrid para estudiar, en una primera y rápida aproximación, cómo cambian algunos de esos usos y costumbres, empujados por la fuerza de la moda, por eso que hoy se llama "globalización" (y que ya existía por entonces con otro nombre) y por el influjo de los nuevos procesos ideológicos que, a pesar de los refractarios a los cambios, eran conocidos en la capital.
\end{abstract}

Si observamos las costumbres de la clase alta vemos que sus miembros se reunían en salones y tertulias mientras los otros lo hacían en las cocinas y en las casa puerta; unos y otros frecuentaban los teatros y tenían a menudo gustos similares. En los recientes cafés y en las botillerías se mezclaban, mientras que las tabernas parecen haber sido casi de uso exclusivo de los más pobres. En fondas y mesones tampoco era difícil encontrarlos juntos, puesto que aún, cuando estaba acabando el Antiguo Régimen, las diferencias y distancias no eran tanto espaciales como morales, de reconocimiento de la condición.

Había una forma de vivir, tanto entre los pudientes como entre los que no lo eran, que se valoraba como la correcta, conforme a la condición social de cada uno y al hecho de ser español y madrileño. Lo castizo no es un invento de zarzueleros tardodecimonónicos; viene de más atrás, aunque el término se acuña en el siglo XVIII, y no sólo para referirse a un tipo de lenguaje que se considera el correcto y cabal: la indumentaria, las formas de conducta, los valores éticos, los gustos musicales y estéticos, alimenticios y de todo tipo tenían su marchamo castizo ${ }^{1}$. Por

\footnotetext{
${ }^{1}$ En La comedia española defendida, Luis Jayme escribía: "He visto una disertación contra nuestras comedias y una comedia nueva, para ejemplo de cómo se han de formar según arte. Uno y otro me enfadó y diome la gana de escribir esta carta. Y nada se me dará de que no agrade a los críticos, porque no tengo genio ni tiempo
} 
eso otras maneras, nuevas costumbres, nuevas palabras y formas de vestir, en tanto que posibles amenazas para acabar con un orden de cosas aceptado por ciertos sectores, se rechazaron a veces de modo burlesco y crítico.

Esa amenaza era la temible "civilización", palabra que se documenta - por supuesto de forma satírica- por primera vez en España en 1763, en un sainete de Ramón de la Cruz así titulado, La civilización. La civilización introdujo en España y sobre todo en aquellas ciudades que estaban abiertas a las novedades, como eran Madrid, Barcelona, Sevilla o Cádiz, problemas éticos, de conducta y de todo tipo porque se resquebrajaban las formas de vida tradicionales. Los debates sobre este asunto se intensificaron desde finales de los años cincuenta.

Pero, ¿qué era la civilización entonces? ¿Qué significaba esa palabra para los hombres del Setecientos? Nos vamos a encontrar con dos posturas generales al respecto, pero hay más y lo que interesa son los matices.

La palabra "civilización" y los hechos sociales y culturales que conlleva se impusieron como forma histórica, como tiempo. Frente a un Antiguo Régimen estático o de ritmo lento en la mayoría de sus valores y formas de vida, la civilización propone aceleración, movimiento, opinión, duda, variedad, debate, todo lo cual cuestiona o altera lo que se entendía como "genio nacional. Civilizar era un objetivo de la Ilustración, tanto en España como en otros países. Romá y Rosell lo indica en Las señales de la felicidad de España: a los gobiernos compete infundir a la plebe aquellos sentimientos de honor que la civilizan" (1768: 138) ${ }^{2}$. Esta manera de ver las cosas supone, evidentemente, cambios e implica un contraste entre las naciones civilizadas y las salvajes (el binomio se encuentra con frecuencia al referirse a los países americanos, pero también dentro del continente europeo y, sobre todo, cuando se habla de propuestas sociales). Por eso, el proceso de civilización deberá ir acompañado de cambios educativos, ya que, como escribió Montengón, se necesitan muchos conocimientos "en el uso de la sociedad civilizada" (1801: 4). Por otra parte, los pueblos civilizados se consideraban más fáciles de gobernar, según el economista Antonio Muñoz (1769: 101), mientras que su moral se volvía más "flexible y cómoda", al decir de Moratín (Maravall 1991: 221).

Pero esto, que es la postura "natural" de un sector de la Ilustración, encuentra contestación en otro grupo ilustrado, más sensible a las nuevas

para la disputa. A estos les cedo, desde ahora, el campo: hablo sólo con los españoles castizos, amantes de nuestros sabios poetas cómicos" (1762: 5).

${ }^{2}$ Maravall (1991) aporta otros testimonios. Debe verse también Escobar (1982 y 1984) y Álvarez de Miranda (1992). 
formas de conducta y menos propicio a la interferencia del Estado y de las instituciones en la vida de las personas, de manera que el modelo civilizado ideal de este grupo, en el que figuran historiadores y novelistas, es precisamente el salvaje, el "buen salvaje" que, por su inocencia y no estar corrompido por las maneras del progreso, encarnaría los valores de hombría de bien que, en principio, había propuesto la Ilustración.

La "civilización" era el estado moderno al que aspiraba un sector de la población; "civilizar" era el proyecto ilustrado y los medios que se ponían en juego para conseguir ese estado, y "civilizado" era el país o el reino que ya lo había conseguido.

Sin embargo, estos objetivos educativos, religiosos y de todo orden eran vistos por sectores refractarios como formas negativas de conducta: tertulias, cafés, reuniones en salones, las modas en la indumentaria, podían entenderse y se entendían, proyectando una idea política, como formas de hipocresía, irreligiosas y, desde luego, no españolas (cuando no antiespañolas). Los tratados que desde mediados de siglo se publican sobre normas de educación (que van desde enseñar a usar los cubiertos hasta indicar cómo comportarse con los iguales, inferiores o superiores en la escala social) se entendieron a menudo como ataques a la moralidad nacional, a la naturalidad y, por tanto, a la sinceridad y franqueza que eran notas de la esencia española, del "genio nacional. Se denunciaba que importaba más "parecer" que "sern. Y se planteaba así un problema que está en el centro de la modernidad: la posibilidad del hombre de ser muchos, de variar según las circunstancias de cada momento, frente a la condición abstracta y "de una pieza" que se tenía del hombre en el Antiguo Régimen, como trasunto de una esencialidad teológica.

Maravall en su estudio sobre la palabra "civilización", recurre al sainete de Ramón de la Cruz para indicar algo de lo expuesto hasta ahora y enfatizar la repulsa del medio rural a las novedades que llegan desde la ciudad, en el caso de la ficción, desde Madrid:

vendría a poner de manifiesto la tensión conflictiva que se había producido entre la ciudad y el campo, el recelo y hostilidad de los campesinos contra las gentes de esa ciudad desde la que querían imponerse las reformas. En consecuencia, los elementos populares rechazan las novedades cultas, debido a razones económicas (al comparar su penuria con la holgura de los poderosos cuya presión soportan) y a razones ideológicas (la mentalidad arcaizante del campo, en el Antiguo Régimen incomparablemente más fuerte que hoy). Y esta repulsa es utilizada por los elementos reaccionarios contra los elementos progresivos de la ciudad (1991: 225).

Es obvio que Maravall, que hace estas reflexiones al hilo del argumento del sainete (que se desarrolla en una aldea), tiene razón, pero la 
disyuntiva ideológica que plantea y que ejemplifica con el binomio "ciudad/ campo" se daba también en la propia ciudad. Si pocos años después de estrenar Ramón de la Cruz su sainete, la mayoría de los madrileños, en lo que se ha llamado el motín de Esquilache, se negó a dejar los grandes sombreros y sus largas capas fue por esa razón. Dentro de la ciudad existía, evidentemente, esa mentalidad arcaizante y defensiva de la que participaban elementos de todos los grupos sociales, y el mismo autor, desde su obra, deja constancia de ello, al tiempo que señala lo poco avanzado que está el proceso civilizador en la Corte: "supongo que en una aldea/ no es mucho falte lo que/ en la Corte no se encuentra" (1915: 97b); "aún está en paños menores/ de educación y de ciencias" (1915: 96a).

Es evidente que el público estaba al tanto de la polémica sobre esas formas de modernidad que se pretendían introducir - $y$ por las que en general tomaba partido contrario-, ya que, de no ser así, un autor que basaba su supervivencia en la aceptación de sus obras, no la habría titulado de tal manera, arriesgándose a fracasar sin saber que habría una recepción adecuada ${ }^{3}$.

El sainete pasa revista a una serie de tópicos centrales de la conducta moral, de la ideología y de las relaciones de los madrileños -que son los modernos-, frente a las costumbres que mantienen los payos de la aldea ${ }^{4}$. La idea según la cual lo esencial de las naciones está en las clases bajas y populares, no es romántica; nace en el Siglo de las Luces, y así, en esos aldeanos ideales, "resplandecen las ideas/ de religión, verdad,/ aplicación e inocencia" (1915: 95b), características del ser nacional que amenazan los madrileños modernos. Su lenguaje, el de los aldeanos, es radicalmente distinto del de aquellos ciudadanos que van a civilizarlos; su ropa es diferente, hasta el punto de indicar uno de ellos al ver a unas majas y un abate: "no entiendo la vestimenta" (98a). Las nuevas leyes urbanas civilizadoras serán leyes torcidas, algunas de ellas sobre todo porque alteran la relación entre los sexos. El famoso cortejo tiene su espacio en los versos, pero sobre todo se extiende más Ramón de la Cruz en anotar los cambios que permitían a la mujer de ciudad una vida más

\footnotetext{
${ }^{3}$ Escobar (1984) al contextualizar el estreno del sainete mostró la polémica existente ese año 1763 entre los periódicos El Pensador (progresista) y El escritor sin título (conservador), respecto de si "España estaba por civilizar". Ecos de la polémica se encuentran en la obrita: "toda esta tierra/ está por civilizar" (1915: 95b); "Si es defecto natural/ (según dicen malas lenguas)/ de toda España, por qué/ extrañáis que en una aldea falte?" (1915: 95b).

${ }^{4}$ Payo era tanto el castellano de cerca de Madrid, como el andaluz (Caro Baroja 1980: 24).
} 
libre, que se manifiesta en que puede asomarse "sin celosía a la reja", "andar sola por la calle", "tocar la mano/ de un hombre" (98b) en la escalera oscura para no caerse. Toda una enumeración de "rarezas/ del siglo pasado" que se han olvidado y por las que algunos aldeanos protestan con escándalo, lo cual callará el marqués civilizador pidiendo que "no se meta[n]/ en moralizar asuntos" (99a).

El espacio que Cruz dedica a los cambios en las relaciones entre hombres y mujeres es amplio, y en él opone claramente dos modelos de conducta femenina. Por un lado, el de las que toman partido por lo nuevo; por otro, el de las que guardan las tradiciones y piden permiso a sus maridos para bailar, cantar o realizar cualquier acción: "como mi marido quiera,/ yo bailaré alguna cosan, a lo que responde la petimetra: "El pedir esas licencias/ se ha mandado recoger".

No se hace esperar la réplica del marido: "Será entre gente suelta" (99a).

Si Cruz dedica tanta atención a este aspecto es por la importancia que tenía la mujer en el proyecto reformador y porque de su aceptación o no de las novedades dependía gran parte del cambio de la sociedad. La mujer era uno de los pilares de esa reforma, hasta el punto de señalar Nifo en su traducción de El amigo de las mujeres que el trato de la mujer civiliza al hombre 5 . Sin embargo, Ramón de la Cruz intenta contrarrestar este proceso de "afeminamiento" que se daba en los hombres de Madrid y otras ciudades, producido por el trato continuado con mujeres, en lugares y espacios que hasta entonces estuvieron vedados al varón. De esta necesaria separación, de cuáles eran los espacios públicos y privados de unos y otras y de cuáles y cómo habían de ser las relaciones en ellos, queda constancia también en su sainete - de las botillerías, por ejemplo, dice una serie de cosas, para acabar su demonización indicando que "allí van mujeres y hombres/ y dicen que se refrescan;/ y hay unos lances ¡qué lances!/ ¡Dios nos libre y nos defienda!» (1915: 100a)—; pero en los textos que denuncian la vida en tertulias y en los tratados de civilización que entonces se traducen y publican quedan las huellas de los cambios que paulatinamente se estaban dando en esos espacios y en las maneras.

Alteraciones que se manifestaban también en la disposición y adorno de las casas, en las zonas de éstas que se dedicaban a la vida familiar (privada) y a la de sociedad, y, por supuesto, en las decoraciones: muebles, tapices, adornos. Concha Herrero (1996: 81-82) indica que ese cambio, que se dio primero en los palacios y residencias reales, se reflejó así

5 "Si viviéramos apartados de las mujeres, seríamos absolutamente diferentes de lo que somos. El cuidado que ponemos en adquirir sus favores, civiliza y endulza aquel tono adusto [de los hombres]" (1763: 12). 
mismo en las casas de nobles y cortesanos, que venden, desde mediados de siglo, "los muebles antiguos a los prenderos y destierran de toda la casa lo que tenga el más leve resabio de añejo", como señala en 1760 Nifo desde el Cajón de sastre (tomo IV: 77- 78). Los cambios indican el paso de las modas, pero las reflexiones, siempre un poco exageradas, sobre éstas y el lujo ponen de relieve la complejidad del momento, pues lo nuevo impone un ritmo y la consideración del pasado como cosa antigua, aunque antiguo y pasado podía ser algo relativamente reciente, como se lee en El Censor del 15 de enero de 1784, donde se acuña el término "anticuación" para referirse al momento en que las novedades se quedan viejas: "se tendrá cuidado particular en avisar el día de su anticuación" (1784: 150), escribe P.H. Como consecuencia de esta variación del gusto, de considerar antiguas unas formas decorativas, se dio un aluvión de ventas de esos objetos.

Los encargados de velar por la moral han visto siempre como una amenaza cualquier cambio, cambios que a menudo suponían una pérdida de su poder y una cesión de éste a sectores que habitualmente eran "inocentes" como los aldeanos que el marqués quiere civilizar. Cuando el de Esquilache quiso acortar las capas y cambiar los sombreros, por razones tanto de higiene como de policía, sus contrarios políticos - nobleza española tradicionalista partidaria de no cambiar la política fiscal que él abanderaba y que veía disminuir su intervención en el gobierno- movilizaron a las masas calificando al marqués de antiespañol y sus reformas de no cristianas, incluso, como tenía importantes negocios, le acusaron de judío. Lo mismo había de suceder con muchas otras normas que intentaban regular la vida social y económica ${ }^{6}$.

La civilización, el progreso, traía consigo una reglamentación nueva, de la cual se derivaban prohibiciones y legislación de aspectos que hasta ese momento se habían mantenido fuera de dicho impulso. El furor de legislar del que se ha hablado era una manifestación de modernidad y de progreso. Se abrían cafés, por ejemplo, para inmediatamente dictar normas y regulaciones que afectaban al modo de estar, de vestir, de hablar en ellos, y se prohibía la entrada de personas desocupadas y ociosas.

Este afán por legislar, que refleja un interés por ordenar la vida, se centró mucho en aquellos aspectos que se entendían como suntuarios o propios del lujo, indicándonos que en la cultura del momento se problematizó lo que hasta entonces se había tenido por superficial. Era

\footnotetext{
${ }^{6}$ Sobre el motín, véase últimamente (Gelz: 1999).
} 
precisamente eso lo que daba riqueza, aunque gran parte de los beneficios salieran del país. Al mismo tiempo, este interés por lo superficial, por la imagen, como siempre, provocaba problemas morales y de relación social.

El cambio que se daba en la valoración de las indumentarias, es decir, ante los signos externos que identificaban a las personas y proporcionaban información sobre su procedencia social, y que alteraba la fiabilidad de esa información — problema que venía de atrás, así como la legislación sobre calidades y adornos de los vestidos-, llevó a los Borbones a concebir una serie de normas que, desde la moral y la ideología, intentaron aminorar esos excesos y otorgar o recuperar la seguridad de la información, y así se reglamentó —otra vez, pero con razones e implicaciones nuevas- el tipo de tejidos que se podían vestir y utilizar, el número y tipo de adornos de los trajes, el de las mulas que podían tirar de un coche, cómo debían vestir los cocheros y lacayos, etc. Y todo esto con unas importantes multas y castigos, si se cometían infracciones.

Esta actitud reguladora, que también buscaba mejorar la industria nacional, llevó, a finales del reinado de Carlos III, a proponer un traje para las mujeres, que al parecer eran las que más gastaban en adornos. La idea se expuso en un Discurso sobre el lujo de las señoras y proyecto de un traje nacional. Aunque algunos piensan en una mujer como autora, tras las iniciales M.O. parece estar el oficial de contaduría de la Fábrica de Tabacos de Sevilla José de Espinosa y Brun ${ }^{7}$, que ofrecía al conde de Floridablanca la reglamentación del lujo y la posibilidad de reconocer a cada cual por lo que era, no por lo que parecía, que era otro de los cambios que los nuevos tiempos traían y que atemorizaba a los amigos del orden. El librito se publicó "De orden superior" en la Imprenta Real, lo que da cuenta del interés que la superioridad tenía en este asunto. Desde otro punto de vista, el proyecto se ajusta plena aunque tardíamente a los esquemas del arbitrismo.

El autor señala bien, por defecto, que la movilidad social, el deseo de aparentar lo que no se es y el interés por el aspecto exterior -es decir, por la creación de una apariencia o máscara que tanto oculte y proteja la personalidad como proyecte una imagen deseada-, lleva a no conocer la clase ni la condición de las personas; algo que sí sucedía antes, en los buenos tiempos en que el español (y por ende el madrileño) era fiel, claro y recto en sus valores, expresiones y conductas. Por eso es

\footnotetext{
${ }^{7}$ Para el nombre del autor, véase Archivo Histórico Nacional, Estado, 323 (10). Aguilar Piñal (1984: 205). Ficha 1501.
} 
necesario el traje nacional, porque se podrá distinguir por el exterior a las personas, en este caso, a las mujeres, así como su puesto en la jerarquía social. Hay que tener presente que Espinosa, por el momento, no señala traje concreto al "estado general", pero considera que también debe ser incluido en la reforma en un estadio posterior.

Este interés por reglamentar la indumentaria, el porte, pone de relieve la importancia que adquiría en aquellos años de transición del Antiguo Régimen hacia una sociedad moderna la representación del individuo en sociedad, la distancia que se establecía entre el hombre en privado y en público. Todo esto se percibe en las páginas del Discurso sobre el lujo de las señoras, en las que el autor no admite ni siquiera la posibilidad de aceptar el lujo porque "fomenta la industria y las manufacturas, [por]que hace florecer el comercio" (1788: 16); para el autor son palabras huecas. La dimensión económica del asunto sólo le interesa en tanto en cuanto puede ejercer un nacionalismo mediante el cual pedir que los pocos adornos de sus trajes nacionales y éstos mismos se fabriquen con materiales del país.

Preocupado por las relaciones entre hombres y mujeres explica que su proyecto será también ventajoso porque permitirá un mayor número de matrimonios, ya que, por lo que cuenta Espinosa, muchos eran los hombres que no se casaban entonces por miedo a no poder mantener el lujo de sus mujeres (24). Algo similar, como parte de la representación exterior, ocurría con el deseo de tener coche en Madrid. Son numerosos los testimonios, literarios y jurídicos, que reflejan las quejas de los maridos ante el gusto de las esposas por pasear en aquéllos, con el consiguiente detrimento de la economía doméstica, y muchas también las referencias a lo perjudicial que esto era para la ganadería y la agricultura (Álvarez Barrientos 1985).

Apoyado en el intento de volver a hacer creíble el valor informativo de la apariencia, señal de que se había diferenciado lo que se era y lo que se parecía, establece Espinosa que, para que las damas más importantes y nobles se distingan de las demás, "a similitud de la tropa", lleven "divisas", galones y distintivos (37-38), y hace una catalogación femenina por clases, empleos, nobleza y riqueza de sus padres y maridos, a la que deberá arreglarse ese traje nacional, que será de tres tipos: uno de gala, denominado "a la española"; otro mediano o "a la carolina" y uno sencillo, "a la borbonesa o a la madrileña". M.O. no duda que su propuesta resolverá los problemas económicos que el excesivo lujo produce y que contribuirá a la felicidad nacional.

El proyecto, bien visto por Floridablanca y por el mismo rey, pasó a la Junta de Damas de la Real Sociedad Económica Matritense para que 
establecieran un premio y poder ofrecer a las ciudadanas súbditas unos modelos de trajes nacionales.

Pero las damas estudiaron el proyecto y lo rechazaron: les parecía, entre otras cosas, que la nobleza no debía exhibirse mediante galones como en el ejército, que si sería difícil sujetar a los hombres a un solo traje, más lo sería que ellas lo hicieran si antes no existía el ejemplo masculino. También le parecía mal a la Junta que hubiera una comisión, como pretendía Espinosa, para perseguir las infracciones que pudieran cometerse en cuanto a los adornos y calidades. Terminaban su informe señalando que "el grave desorden que se experimenta en cuanto a trajes y adornos" sólo se remediará cuando "mejoren las costumbres por medio de la educación", que es el punto en el que insisten los mejores ilustrados ${ }^{8}$.

Fue, en efecto, en el reinado de Carlos III cuando se legislaron estos extremos de manera más decidida y sistemática, buscando siempre "la pública felicidad" (II, 1788: 168), como escribía Sempere y Guarinos, historiador del lujo en España. Es decir, buscando el reflejo en la población del proceso de civilización.

Si en La civilización, el en teoría conservador y no ilustrado Ramón de la Cruz niega el progreso económico que representan el lujo y ciertas modas utilizando argumentos religiosos, lo hace de un modo muy similar al que empleará veinte años después el ilustrado ortodoxo y funcionario Juan Sempere y Guarinos en su Historia del lujo, que se arregla aa las máximas más puras de nuestra sagrada religión" (I, 1788: 6). Sempere y Guarinos, historiador de la economía, abogado, liberal según los momentos, monárquico siempre, que medró de forma extraordinaria con sus escritos, al trazar una historia del lujo hizo en realidad una historia moral de las costumbres, en la que es partidario de la moderación y la austeridad, de la autenticidad que, tópicamente, adjudica a nuestros antepasados. Pero da también indicios, a veces exagerados (lo cual es un síntoma de en qué consistía el proyecto), de cómo cambiaba la sociedad madrileña, en tanto que sede de la Corte:

\begin{abstract}
Madrid, Corte de los reyes de España [...], estaba sin policía; llena de inmundicias; sin luz de noche; sin buenos paseos ni más diversiones diarias que el tenderse a la larga a tomar el sol o un teatro licencioso y corrompido, tanto en la moral de las composiciones, como en la representación y conducta de los cómicos y sobrada libertad de los espectadores.
\end{abstract}

${ }^{8}$ Este informe se encuentra en el ejemplar R-33985 de la Biblioteca Nacional de Madrid. Años después, esta actitud moral e ideológica, respecto del traje, se politizará, y será un signo de identificación. Así lo hacer ver repetidas veces Antonio de Capmany en 1808 (1988: 90, 116, 137). 
Y añade, cambiando el objeto de su reflexión:

De artes, fábricas, edificios, comercio, establecimientos útiles, tanto para la comodidad de los ricos como para el socorro de los pobres y recogimiento de los vagamundos y mendigos viciosos, había muy pocos o estaban mal administrados y dirigidos (II, 1788: 168-169).

Podemos pensar lo que se nos antoje de los calificativos empleados por Sempere, pero, para el objeto de esta exposición, me interesa señalar unos rasgos determinados. La civilización de Madrid y de sus costumbres se entiende como un proceso de racionalización del comportamiento. El orden, la moderación, la austeridad, la moralidad, todo ello apunta hacia esa racionalidad que quiere controlar y reducir a leyes unas conductas instintivas por las que ahora, con la Ilustración del buen rey Carlos III, hay que sentir vergüenza.

En la base de esta actitud se encuentra la convicción de que la verdad, el auténtico modelo vital valorado, está en lo sobrio, en lo moral y virtuoso, que se opone al exceso corrupto y voluptuoso del mundo barroco. Este intento civilizador se extendió a todos los campos sociales, desde la educación a las costumbres, desde el gobierno a las artes y llegó también a la Iglesia como institución, con el consiguiente rechazo. Así, por ejemplo, los payos de Ramón de la Cruz sienten escrúpulos ante las nuevas normas que se quieren introducir en su pueblo, por lo que no consentirán, como grado último de perversión civilizadora, "que a civilizar la Iglesia/ se atreva nadie" (1915: 100b), ya que esta intención es la funesta causa de ociosidad, escándalo y decadencia de los pueblos (100b).

La civilización de las costumbres de majos y majas era vista por estos como afeminamiento, como decadencia de la raza ejemplificada en petimetres y petimetras, también conocidos como "grantontos" (97a); sin embargo, haciendo énfasis en el eje axial ya señalado, los reformistas insistían en "el grande influjo que tienen en las costumbres y cultura de las naciones la belleza, la regularidad y el ornato de los objetos públicos, el orden de las concurrencias y sobre todo el aseo y propiedad en el vestido [...], y así trató [el rey] desde luego de poner en ellos el orden conveniente" (II, 1788: 169. La cursiva es mía).

Desde esta perspectiva explica Sempere el intento reformista de Esquilache, al que ya he aludido, y otros referentes a fiestas y diversiones públicas. Es necesario poner orden en las costumbres y, por lo mismo, Jovellanos es partidario de que haya diversiones públicas en ciudades y lugares para que, además, no vengan a la Corte los nobles aburridos, que más tarde traen a la familia, flujo constante aal centro de población y riqueza" que abandona "los extremos" (1997: 192). El asturiano piensa 
en establecer "cafés o casas públicas de conversación y diversión cotidiana». En ellos se jugará, se leerá el periódico y se conversará, a pesar de la legislación que lo prohibe, dando entrada a nuevos espacios de sociabilidad urbana, desconocidos hasta entonces, que aliviarán la necesidad de los ociosos, al tiempo que mantendrán la riqueza en la periferia, pues se evitaría el flujo de los pudientes hacia el centro.

Ese interés por ordenar la vida o por reordenarla, por hacer que la capital tuviera un aspecto nuevo y moderno, que la acercara al de las cortes europeas, produjo una serie de leyes que suponían cambios en la vida y costumbres urbanas. Desde los tiempos de Carlos IV, se exigió pasaporte a los transeúntes, se reguló la construcción y el levantamiento de andamios, se quiso que se cerraran las cortinas de las ventanas que daban a la calle (mostrando un principio de privacidad), se regularon las formas de venta en los mercados. Para aumentar la higiene en la conservación de alimentos, se prohibió que tuvieran agua en los tenderetes, en la que lavaban las legumbres, también se ordenó que se cambiara con asiduidad el agua en que mantenían el bacalao. Se prohibió establecer fábricas como tintorerías, hornos de ladrillos y yeso e industrias que necesitaran combustibles, sacándolas de la ciudad. Para mejorar la educación y convivencia de los habitantes se prohibió que las lavanderas interpelaran a los viandantes, hacer gestos obscenos, silbar a las mujeres, disparar fusiles, lanzar cohetes y muchas otras cosas (Desdevises, 1989: 164-165). Como habrían señalado las damas de la Sociedad Económica, con prohibiciones poco se alcanzaba; era necesario mejorar la educación.

El aumento de riqueza que se percibe en el Madrid de entonces produce alteraciones, no sólo en las capas sociales, cuya movilidad ascendente suele ser criticada, sino también en los valores, y de esto, además de los historiadores, dejaron constancia costumbristas, periodistas y moralistas, todos ellos, por diferentes razones, observadores atentos de la realidad cotidiana. La forma de comer, lo que se comía y bebía, la asistencia a fondas y cafés no fue sólo objeto de la sátira de Larra. Fígaro, en este como en otros casos, se inscribe en una tradición previa.

Sempere indicaba en 1788 que

hasta de unos treinta o cuarenta años a esta parte no se conocía en la mesa la infinita variedad de platos con que ahora se tienta el apetito en las fondas y convitẹs. La aloja y el hipocrás eran todo el surtido de las botillerías; el vestido de los hombres era negro por lo general, con lo cual no había el furor de mudar de colores continuamente, causando ahora sola esta circunstancia un exceso de gasto incalculable. El de las mujeres, antes [...], era más decente y menos dañoso a la salud. Siendo entonces las faldas mucho más largas que ahora, cubrían enteramente el pie, con lo cual no había lugar al extraordinario lujo de medias y zapatos, ni a la provocación que ocasiona esta indecente moda" (II, 1788: 177-178). 
Gasto, economía y moral siempre juntos. No se deslindan los campos, como sí hizo José Cadalso en varias de sus Cartas marruecas, en las que enfoca el problema del lujo desde distintos ángulos, tanto económico, como filosófico y político, ofreciendo soluciones distintas (Véanse las cartas XLI, LXVIII y LXXXVIII).

Del mismo modo que Espinosa y Brun, el valenciano Sempere traza una pintura negativa de la vida, al suponer que los nuevos valores se asientan en bases superficiales, para llegar a su expresión más aciaga cuando escribe:

En cuanto a las costumbres, todavía es mayor la dificultad de decidir cuando han estado más corrompidas. Quien lee la historia con reflexión encuentra que en todos tiempos han sido los hombres generalmente malos, injustos, destemplados, inmodestos; que su propia conveniencia ha sido el ídolo a quien han sacrificado sus afanes; y que los justos y virtuosos siempre han sido muy pocos, comparados con el resto de los demás. Pero se advierte esta diferencia, que en los siglos que llaman bárbaros, los hombres han sido malos sin rebozo y sin detenerse en paliar con los bellos nombres de decencia y civilidad los vicios y desórdenes. En los siglos cultos e ilustrados se dora la maldad, se encubre y, lo que es peor, se levantan talentos atrevidos, espíritus fuertes, que trastornando los más sólidos fundamentos de la moral y con una elocuencia brillante y seductora, no solamente desfiguran los vicios, pintándolos menos feos y abominables, sino que los canonizan temerariamente, colocándolos en el solio debido únicamente a la virtud (179).

Es la hipocresía, el parecer frente al ser. En el discurso de quienes están contra las novedades y los cambios, la civilización, las normas de conducta, se interpretan como formas de hipocresía y disimulo que amparan comportamientos rechazables. En las cortes, escribe Fray Francisco Tizón, se practica la falsa urbanidad "y son más fuertes los incitativos para la simulación, la hipocresía y adulación" "

En esas cortes hay unas figuras nuevas, peligrosas como todo lo nuevo, que, además, teorizan ese comportamiento y viven de manera poco ejemplar. Figuras que a veces en tertulias y reuniones, desde los periódicos y en los cafés, exponen opiniones contrarias a la moral tradicional, que pueden cuestionar los valores y que ellos mismos son, por sus maneras desenvueltas y frívolas, malos ejemplos para la sociedad. Solían ser jóvenes, no respetaban los criterios de autoridad y leían otras cosas. Estos personajes, que predicaban en los lugares señalados, eran los "espíritus fuertes. Es obvio que en épocas anteriores existieron enfrentamientos entre lo antiguo y lo moderno, pero en los años del siglo XviII

${ }^{9}$ En la censura, sin paginar, de la obra de Ignacio Benito Avalle, La urbanidad $y$ cortesia universal. 
este enfrentamiento adquiere unos tintes especiales porque tiende más a romper con un mundo que se ve como caduco, mientras que en las épocas precedentes la pugna no cuestiona del mismo modo el sistema y tiende a ponerlo al día. La autenticidad en las conductas a la que se refería Sempere no parece ponerse en cuestión entonces, y sí ahora, cuando a las normas de educación se le llama disimulo, y cuando los valores que rigen la conducta del hombre van dejando de ser abstractos y generales para adecuarse a las necesidades e intereses de las circunstancias, del aquí y ahora.

El esprit fort francés es el filósofo, el que hace avanzar la sociedad porque piensa, prueba, desmonta tópicos y ejecuta. No es un hombre especialmente erudito, pero sí tiene capacidad de pensamiento y argumentación, y valora la opinión y el juicio por encima de los conocimientos mostrencos. El "espíritu fuerte" es por definición crítico. A esta figura, netamente urbana, de la que nos han dejado numerosos retratos burlescos, se le llamó de muchas maneras. La más conocida, "erudito a la violetan, y sus valores no eran los del respeto a las canas y a las autoridades, sino otros que tenían que ver con la apariencia (cuidaban mucho su imagen), con lo superficial (restaban importancia a lo hasta entonces esencial) $\mathrm{y}$, como señalé antes, daban prioridad al trato femenino. "Los siglos cultos e ilustrados", como llama Sempere al suyo, causan todo tipo de trastornos del orden, porque, "empezando por la educación doméstica, que es la basa de las buenas costumbres y de las virtudes sociales, apenas queda una sombra del respeto, recato y recogimiento con que se criaban los hijos, y de la fidelidad de las mujeres a sus maridos" (183).

Si el "espíritu fuerte" o el bel esprit se mostraba y afianzaba en tertulias, salones y paseos, encontraba fuerte rechazo en otros escenarios. Terreros incorporó ese sentir generalizado a su Diccionario castellano (1786), al parecer compuesto entre 1745 y 1765 , cuando definía así la expresión bello espiritu, en la que distingue los aspectos positivos y negativos de la figura, que son los nuevos, algunos de los cuales expone también Sempere al referirse a esta novedad social:

es del término francés bel esprit, y se toma en dos partes diversas: lo primero, significa un hombre o entendimiento que piensa con brillantez, sin que le falte la solidez y buen juicio, y así viene a ser lo mismo que agudo, ingenioso, entendido; lo segundo, se toma en la mala parte, por un hombre de falso brillante, vano, jactancioso y afectado, o agudo sin solidez, de modo que se aparta de la verdadera agudeza, que nunca podrá estar sin ser sólida.

Esta figura era además una agresión a la Iglesia y a los valores que propugnaba la fe católica puesto que, en contra de lo aconsejado por 
ésta, hacía ostentación de sus conocimientos y de su capacidad de pensamiento, es decir, cometía pecado de orgullo.

En esta época se asiste a la elaboración de un discurso, tanto de la modernidad como de la reacción, que se consolidará en los años finales del siglo, cuando las actitudes ante la Revolución Francesa, la Guerra de la Independencia y las Cortes de Cádiz fuercen el enfrentamiento de ambas facciones, aunque no siempre las posturas o las oposiciones fueran excluyentes. Precisamente, coincidiendo con los años de la Revolución, el liberal León de Arroyal señalaba que "la civilización general" inundaba insensiblemente las costumbres, a pesar de "los estorbos que a cada paso halla en la barbarie.. Y, si Ramón de la Cruz había indicado que la civilización era la causa de la degeneración de la sociedad, Arroyal entendía lo contrario: "la civilización de los pueblos [es] causa principal de su opulencia" (1971: 154, 165).

Progreso y modernidad son palabras sinónimas en esos años y ponen de relieve el carácter centralista y unificador de la Ilustración que se manifiesta en el concepto de civilización, que es un modelo de vida. La civilización, que irradia de determinados centros ideológicos y de poder, pretende acabar con las diferencias, con las formas antiguas, desde su fe en su capacidad para transformar la realidad. De hecho el plural "civilizaciones" sólo se admite entrado el siglo XIX, indicando ya la fragmentación del universalismo ilustrado. Para ese momento del siglo nos encontraremos ante la vivencia amarga, romántica, de la modernidad. En coherencia con este planteamiento, esa capacidad para cambiar el mundo está detrás de la enorme importancia que se da al aspecto exterior.

El hombre moderno ilustrado, con su fe en el progreso y en la civilización, no acepta pasivamente la realidad y cree que puede cambiarla. El Madrid de la segunda mitad del siglo XviI fue un campo de pruebas en el que se llevó o se intentó llevar a cabo ese proceso de civilización que, con distintas velocidades, implantaba una nueva sociedad en Europa, cuyos criterios de valoración se basaban cada vez más en factores profesionales. Fumar tabaco frente a tomar rapé, preferir el chocolate al té o al café, ser manolo o petimetre, aceptar o no los periódicos y nuevos lugares de sociabilidad, usar sombrerito o mantilla, preferir el brasero o la chimenea, no fueron simples anécdotas que contar hoy; tras esas elecciones, que se seguirán planteando de forma conflictiva en el Romanticismo, había una carga ideológica, una postura ante los cambios civilizadores y una opinión política que trascendía una apuesta vital. 


\section{BIBLIOGRAFÍA CITADA}

Aguilar Piñal, Francisco. 1984. Bibliografía de autores españoles del siglo XVIII, III. Madrid: CSIC.

ÁlVAREZ BARRIENTOS, JOAQUín. 1985. "Literatura y legislación sobre coches en el Madrid del siglo XVIII". Anales del Instituto de Estudios Madrileños, 22: 201-224.

Álvarez de Miranda, PEDro. 1992. Palabras e ideas: el léxico de la Ilustración temprana en España (1680-1760). Madrid: RAE.

ARroyal, LEÓN DE. 1971. Cartas económico-políticas. Ed. Caso González, José Miguel. Oviedo: Universidad.

AVAlle, IgNACIO BeNito. 1744. La urbanidad y la cortesía universal que se practica entre las personas de distinción. Traducida del idioma francés al castellano por D.... Madrid: sin imprenta.

CADALSO, José. 1982. Cartas marruecas. Noches húgubres. Ed. Joaquín Arce. Madrid: Cátedra.

CAPMANY, ANTONIO DE. 1988. Centinela contra franceses. Ed. Françoise Etiènvre. London: Tamesis Books.

Caro Baroja, Julio. 1980. Temas castizos. Madrid: Istmo.

CruZ, RAmón DE LA. 1915. Sainetes de.... de. Emilio Cotarelo y Mori. Madrid: Nueva Biblioteca de Autores Españoles, 2 vols.

DESDEVISES DU DEZERT, GEORGES. 1989. La España del Antiguo Régimen. Madrid: FUE. DíAz Plaja, Fernando. 1988. La vida cotidiana de los Borbones. Madrid: Espasa-Calpe. ElíAs, NORBERT. 1988. El proceso de la civilización. México: FCE.

EsCOBAR, José. 1982. "Civilizar, civilizado y civilización: una polémica de 1763", en Actas del Séptimo Congreso de la Asociación Internacional de Hispanistas: I, 419- 27. Roma: Bulzoni.

- 1984. "Más sobre los orígenes de civilizar y civilización en la España del siglo XVIII. Nueva Revista de Filología Hispánica 33: 88-114.

GeLZ, ANDREAS. 1999. "Les lumières du scandale: le motín de Esquilache (1766), conflit culturel et expérience d'altérité au xvine siècle espagnol,, en Bell, David A. y otros (eds.) La recherche dix-huitiémiste. Raison universelle et culture nationale au siécle des Lumières: 149-178, Paris. Honoré Champion.

Hamilton, ARTHur. 1926. A Study of Spanish Manners, 1750- 1800 from the plays of Ramón de la Cruz. Urbana: The University of Illinois.

Herrero, Concha. 1996. "La Real Fábrica de Tapices de Madrid y las innovaciones en tiempos de Francisco de Goyan, en AA.VV., Realidad y sueño en los viajes de Goya: 69-85 Zaragoza: Diputación y Consorcio Goya Fuendetodos.

JAYME, LuIs. 1762. La comedia española defendida. Madrid: Imp. del Diario.

Jovellanos, MelChOR GASPAR. 1997. Espectáculos y diversiones públicas. Informe sobre la Ley Agraria. Guillermo Carnero (ed.). Madrid: Cátedra.

KanY, Charles E. 1970. Life and Manners in Madrid 1750-1800. New York: AMS Press. MARAVALL, JOSÉ ANTONIO. 1991. "La palabra 'civilización' y su sentido en el siglo XVIII", en Estudios de bistoria del pensamiento español. Siglo XVIII: 213-232 Madrid: Mondadori.

Montengón, Pedro DE. 1801. Frioleras eruditas y curiosas. Madrid: García y Cía.

MuÑoz, ANTONIO [pseudónimo de Enrique Ramos]. 1769. Discurso sobre la economía politica. Madrid: Joaquín Ibarra. 
Nifo, Francisco MARIANO. 1763. El amigo de las mujeres, traducido del francés por.. Madrid: Gabriel Ramírez.

O., M. [pseudónimo de José de Espinosa y Brun]. 1788. Discurso sobre el lujo de las señoras y proyecto de un traje nacional. Madrid: Imp. Real.

ROMÁ Y ROSSELL, FrANCISCO. 1768. Las señales de la felicidad en España. Madrid: Antonio Muñoz del Valle.

SEMPERE y GuARINOS, JuAN. 1788. Historia del lujo y de las leyes suntuarias de España. Madrid: Imprenta Real, 2 vols.

STEINER, GeOrGE. 1980. Después de Babel. México: FCE. 